\title{
Adeno-associated virus-mediated heme oxygenase-1 gene transfer suppresses the progression of micronodular cirrhosis in rats
}

\author{
Tung-Yu Tsui, Chi-Keung Lau, Jian Ma, Gabriel Glockzin, Aiman Obed, Hans J Schlitt, Sheung-Tat Fan
}

Tung-Yu Tsui, Chi-Keung Lau, Jian Ma, Sheung-Tat Fan, Centre for the Study of Liver Disease and Department of Surgery, the University of Hong Kong, Pokfulam, Hong Kong

Tung-Yu Tsui, Gabriel Glockzin, Aiman Obed, Hans J Schlitt, Department of Surgery, University of Regensburg Medical Centre, Regensburg, Germany

Correspondence to: Dr. Tung-Yu Tsui, Department of Surgery, University of Regensburg Medical Centre, Franz-Josef-StraussAllee 11, 93053 Regensburg,

Germany. tung-yu.tsui@klinik.uni-regensburg.de

Telephone: +49-941-9446852 Fax: +49-941-9446802

Received: 2005-09-12 Accepted: 2005-10-26

\begin{abstract}
AIM: To test the hypothesis that enhancement of the activity of heme oxygenase can interfere with processes of fibrogenesis associated with recurrent liver injury, we investigated the therapeutic potential of over-expression of heme oxygense- 1 in a $\mathrm{CCl}_{4}$-induced micronodular cirrhosis model.
\end{abstract}

METHODS: Recombinant adeno-associated viruses carrying rat HO-1 or GFP gene were generated. $1 \times 10^{12} \mathrm{vg}$ of adeno-associated viruses were administered through portal injection at the time of the induction of liver fibrosis.

RESULTS: Conditioning the rat liver with over-expression of $\mathrm{HO}-1$ by $\mathrm{rAAV} / \mathrm{HO}-1$ significantly increased the $\mathrm{HO}$ enzymatic activities in a stable manner. The development of micronodular cirrhosis was significantly inhibited in rAAV/HO-1-transduced animals as compared to controls. Portal hypertension was markedly diminished in rAAV/HO-1-transduced animals as compared to controls, whereas there are no significant changes in systolic blood pressure. This finding was accompanied with improved liver biochemistry, less infiltrating macrophages and less activated hepatic stellate cells (HSCs) in rAAV/ HO-1-transduced livers.

CONCLUSIONS: Enhancement of $\mathrm{HO}$ activity in the livers suppresses the development of cirrhosis.

(c) 2006 The WJG Press. All rights reserved.

Key Words: Cirrhosis; Portal hypertension; Heme oxygenase; Gene therapy; Adeno-associated virus
Tsui TY, Lau CK, Ma J, Glockzin G, Obed A, Schlitt HJ, Fan ST. Adeno-associated virus-mediated heme oxygenase-1 gene transfer suppresses the progression of micronodular cirrhosis in rats. World J Gastroenterol 2006; 12(13): 2016-2023

http://www.wjgnet.com/1007-9327/12/2016.asp

\section{INTRODUCTION}

Heme oxygenase (HO) is a rate-limiting enzyme that cleaves pro-oxidant heme into equimolar amounts of carbon monoxide ( $\mathrm{CO}$ ), biliverdin/bilirubin, and free ferrous iron ${ }^{[1,2]}$. Up to date, three isoforms of $\mathrm{HO}$ have been identified. Among of them, HO-1 and HO-2 are expressed in livers. HO-2 expresses constitutively in hepatocyte and functions as an important enzyme in catalyzing the endogenous and exogenous heme. In contrast, HO-1 is an inducible form of $\mathrm{HO}$ in livers ${ }^{[3]}$. Although expression of HO-1 in the liver is primarily restricted to a subpopulation of Kupffer cells ${ }^{[3,4]}$, the protein is expressed in both parenchymal and particularly non-parenchymal liver cells, and therefore results in higher enzymatic activities of $\mathrm{HO}$ under stress conditions ${ }^{[4]}$. The cytoprotective effects of enhanced $\mathrm{HO}$ activities in liver might be through the mechanisms associated with its catalytic products. All of its three catalytic products can contribute the protective effects of $\mathrm{HO}^{[5-7]}$.

HO-1 was induced in the livers with cirrhosis ${ }^{[8]}$. It was thought to be an adoptive response to oxidative stresses, inflammatory insults of persistent or recurrent liver injury as well as the responsiveness to the increase of intrasinusoidal resistance. HO-1 was mainly expressed in Kupffer cells, sinusoidal endothelial cells, stellate cells and in a part of hepatocyte in livers with cirrhosis ${ }^{[8,9]}$. HO-1 was also expressed in vascular system that might contribute to the development of hemodynamic changes in the rats with cirrhosis ${ }^{[9]}$. In addition, higher levels of $\mathrm{CO}$ production might be associated with the development of hepatopulmonary syndrome in patients with cirrhosis ${ }^{[10]}$. Thus, it becomes controversy whether the expression of HO-1 or enhancement of $\mathrm{HO}$ activities contribute to the pathophysiological changes in the development of cirrhosis, or whether HO-1 functions as homeostatic molecule in controlling of disease progression. To elucidate the role of 
HO-1 in the context of recurrent hepatocellular injury and the development of cirrhosis, here we take the advantage of adeno-associated viral vector to increase the overall $\mathrm{HO}$ enzymatic activity of the liver in a stable manner and to investigate the effects of $\mathrm{HO}-1$ in the disease progression in carbon tetrachloride $\left(\mathrm{CCl}_{4}\right)$-induced cirrhosis model.

\section{MATERIALS AND METHODS}

\section{Generation of recombinant adeno-associated viral vectors (rAAVs)}

rAAVs were produced and purified as previously described ${ }^{[1]}$. In brief, a full-length HO-1 gene originally cloned from the spleen of a LEW rat or the reporter gene GFP was inserted into the vector plasmid to construct pSNAV1/ GFP or pSNAV1/HO-1. $\mathrm{rAAV} / \mathrm{GFP}$ or $\mathrm{rAAV} / \mathrm{HO}-1$ was generated in BHK-21 cells (American Type Culture Collection, Manassas, VA) by transfection of vector plasmid and subsequent rescue rAAVs (serotype 2) by co-infection with recombinant HSV1-rc/ $\Delta \mathrm{UL} 2$, which is essential for viron packaging. A large scale of rAAV was purified as described ${ }^{[12]}$.

\section{Animal model and gene delivery protocol}

Inbred LEW rats (230-250 g) were purchased from the Animal Institute of Medical School Hannover, Germany and were maintained in the Laboratory Animal Unit of the University of Hong Kong. The study was approved by the Committee on the Use of Live Animals for Teaching and Research, the University of Hong Kong. Micronodular liver cirrhosis in LEW rats was induced using a protocol described previously ${ }^{[13]}$. In brief, phentobarbital sodium $(35 \mathrm{mg} / \mathrm{L})$ was given one week before the first dose of $\mathrm{CCl}_{4}$ in order to increase the sensitivity of the rat liver to $\mathrm{CCl}_{4}$ and was present in drinking water in the whole period of induction. A total of 9 doses of $\mathrm{CCl}_{4}(0.2 \mathrm{~mL} / \mathrm{kg}$ per wk) were given to the rats intragastrically. rAAVs $\left(1 \times 10^{12} \mathrm{v} . g\right.$. $)$ was given through the portal vein of rats at the time pentobarbital was given in drinking water and $7 \mathrm{~d}$ before the first dose of $\mathrm{CCl}_{4}$

\section{Liver biochemistry, histology, immunohistochemistry and ELISA}

Serum samples were collected at the end point of experiments. The activities of alanine aminotransferase (ALT) and total bilirubin in the plasma were measured in the Department of Clinical Biochemistry, the University of Hong Kong. Liver samples were snap frozen and stored at $-75{ }^{\circ} \mathrm{C}$ until further applications. Five micrometers of frozen sections were used for hematoxylin and eosin staining, Masson's trichrome staining, and immunohistochemistry. The area of fibrotic tissues in the cross section of livers was measured by the computer software (MetaMorph imaging system, Universal Imaging Corporation, PA) after Masson's trichrome, collagen $1 \alpha$ and fibronectin staining. All measurements were done in a double-blind manner with at least 20 areas/liver (fibrotic area, original $200 \times$ ) in the 5 livers/group. Mouse anti-rat ED1 (infiltrating macrophage), anti-ED2 (tissue residential macrophage), anti-HO-1 (OSA-111) monoclonal antibodies and polyclonal anti-TGF- $\beta 1$, anti-desmin, anti-collagen $1 \alpha$, and anti-fibronectin antibodies (Serotec Ltd., Oxford, UK; Stressgene, Victoria, British Columbia, Canada; Chemicon, Temecula, CA; Santa Cruz, CA) were applied in this study for immunohistochemistry using the standard horseradish peroxidase protocol. Serum macrophage migration inhibitory factor (MIF) level was detected by ELISA according to the instruction of manufacturer (Chemicon).

\section{Measurement of portal and systolic blood pressure}

Animals were anesthesized with ketamine (100 mg/kg, ip) and Rompun $(0.2 \mathrm{mg} / \mathrm{kg}$, ip). Portal pressure and systolic blood pressure were measured by directly introducing $24 \mathrm{G}$ Angiocath $^{\circledR}$ (BD Biosciences, San Jose, CA) into the portal vein or abdominal aorta and connecting with a saline filled strain gauge transducer. The signals were monitored by Colin BP-408 Mark III (Japan) and were set to zero before the measurement.

\section{HO enzymatic activity}

The HO enzymatic activity was measured by the production of microsomal bilirubin in the liver. Frozen samples of livers were homogenized in ice-cold sucrose and Tri$\mathrm{HCl}$ buffer. Microsomal pellet was obtained after centrifugation and was then re-suspended in $\mathrm{MgCl}_{2}$-potassium phosphate buffer. Sample protein was further incubated with the reaction mixture containing rat liver cytosol, hemin, glucose-6-phosphate, glucose-6-phosphate dehydrogenase and NADPH (Sigma-Aldrich, St. Louis, MO) for 60 minutes at $37{ }^{\circ} \mathrm{C}$. The generated bilirubin was measured using spectrophotometry. The level of bilirubin production was demonstrated by the ratio of sample/normal liver.

\section{RNase protection assay}

The mRNA level of target genes was determined by RNase protection assay according to the instruction of manufacturer (RiboQuant kit, BD Biosciences Pharmingen, San Diego, CA). In brief, total RNA of transduced and non-transduced liver samples were extracted and purified using Rneasy kit (Qiagen, Hilden, Germany). Three micrograms of RNA/samples were hybridized with complimentary [ $\left.{ }^{32} \mathrm{P}\right] \mathrm{UTP}$ labeled riboprobes overnight. The probes were digested with Rnase and were loaded on a denatured polyacrylamide gel. The radioactive signals were then detected by exposure to X-ray film (BioMax, Kodak, Rochester, NY) and quantified by phosphorimaging (Strom, Molecular Dynamics, Sunnyvale, CA).

\section{Statistical analysis}

Data were demonstrated as mean \pm SEM. One-way ANOVA was used to compare the difference of means between the experimental groups with the Bonferroni's $t$-test. $P<0.05$ was considered statistically significant.

\section{RESULTS}

\section{rAAV-mediated stable $\mathrm{HO}$ enzymatic activity in rat liver}

To enhance $\mathrm{HO}$ activity in a stable manner, we administered the rAAV carrying rat HO-1 cDNA to the liver through portal injection. After the injection, a large num- 
ber of HO-1 positive non-parenchymal cells were found in both $\mathrm{rAAV} / \mathrm{GFP}$ and $\mathrm{rAAV} / \mathrm{HO}-1$-transduced livers on $\mathrm{d}$ $7\left(17.7 \pm 0.5\right.$ cells $/ \mathrm{mm}^{2}$ versus $10.8 \pm 0.7$ cells $\left./ \mathrm{mm}^{2}, n=3\right)$. However, the number of positive cells decreased dramatically to a level similar to normal livers in $\mathrm{rAAV} / \mathrm{GFP}$ transduced liver on day 30, whereas there was a significantly larger number of HO-1-positive non-parenchymal cells in $\mathrm{rAAV} / \mathrm{HO}-1$-transduced livers $\left(3.9 \pm 0.8\right.$ cells $/ \mathrm{mm}^{2}$ vs $5.8 \pm 1.0$ cells $/ \mathrm{mm}^{2}, n=3, P<0.05$; Figures $1 \mathrm{~A}$ and $\left.1 \mathrm{~B}\right)$. No HO-1 positive hepatocyte was found in both rAAV/ GFP and rAAV/HO-1 treatment groups on $\mathrm{d}$ 7. The expression of HO-1 in hepatocyte was first detected sporadically on d 14 after portal injection of $\mathrm{rAAV} / \mathrm{HO}-1$, whereas there was no HO-1 positive hepatocyte in $\mathrm{rAAV} / \mathrm{GFP}$ transduced livers (data not shown). More HO-1 positive hepatocytes could be detected in $\mathrm{rAAV} / \mathrm{HO}-1$-transduced livers on d $30\left(2.2 \pm 0.3\right.$ cells $\left./ \mathrm{mm}^{2}, n=3, P<0.05\right)$, whereas they remained undetectable in $\mathrm{rAAV} / \mathrm{GFP}$-transduced livers (Figures $1 \mathrm{~A}$ and $1 \mathrm{~B}$ ). To evaluate the biological activity of transduced HO-1 in the livers, we determined the enzymatic activity of $\mathrm{HO}$ by measuring the generated bilirubin of microsomal protein isolated from the livers. There was a significant increase of $\mathrm{HO}$ activity of the rAAVtransduced livers on $\mathrm{d} 7$ (the earliest time point that we detected). Both rAAV/GFP and rAAV/HO-1 transduced livers showed increased amount of generated bilirubin in isolated microsomal proteins. Impressively, the amount of generated bilirubin ( 0.9 fold over the basal level of normal rat liver) remained elevated in the $\mathrm{rAAV} / \mathrm{HO}-1$ treatment group and sustained for over 3 mo of observation time. In contrast, the amount of generated bilirubin decreased to the level of normal rats in the rAAV/GFP treatment group on $\mathrm{d} 14$. (Figure 1C). This suggests the specificity of $\mathrm{rAAV} / \mathrm{HO}-1$ in the induction of stable $\mathrm{HO}$ activity in rat liver.

\section{Enhancement of $\mathrm{HO}$ activity suppressed the development of cirrhosis in rats}

Intragastrically administration of $\mathrm{CCl}_{4}$ to adult LEW rats for 9 wk resulted in the formation of micronodular cirrhosis. To further evaluate the effects of elevated HO activity on the development of cirrhosis, we examined various parameters relating to cirrhosis after over-expression of HO-1 in rat liver by rAAV gene transfer (Figure 2A). Histological examination showed massive amount of fibrotic tissues accumulated in the portal tract areas of non-transduced or $\mathrm{rAAV} / \mathrm{GFP}$-transduced livers and led to the formation of micronodular cirrhosis accompanied with portal hypertension and lower systolic blood pressure in the majority of rats. $\mathrm{rAAV} / \mathrm{HO}-1$ gene transfer markedly diminished the amount of accumulated fibrotic tissues as shown in Masson's trichrome (MT) staining and immunohistochemistry. No micronodular cirrhosis was formed and only minimal fibrotic tissues could be found in the portal tract areas of $\mathrm{rAAV} / \mathrm{HO}-1$-transduced livers (Figure 2B). Analysis of fibrotic areas using the computer software showed that there was significantly less fibrotic element deposition in the $\mathrm{rAAV} / \mathrm{HO}-1$-transduced liver $(7.9 \% \pm 0.9 \%$ by MT staining, $3.1 \% \pm 2.6 \%$ by collagen $1 \alpha$

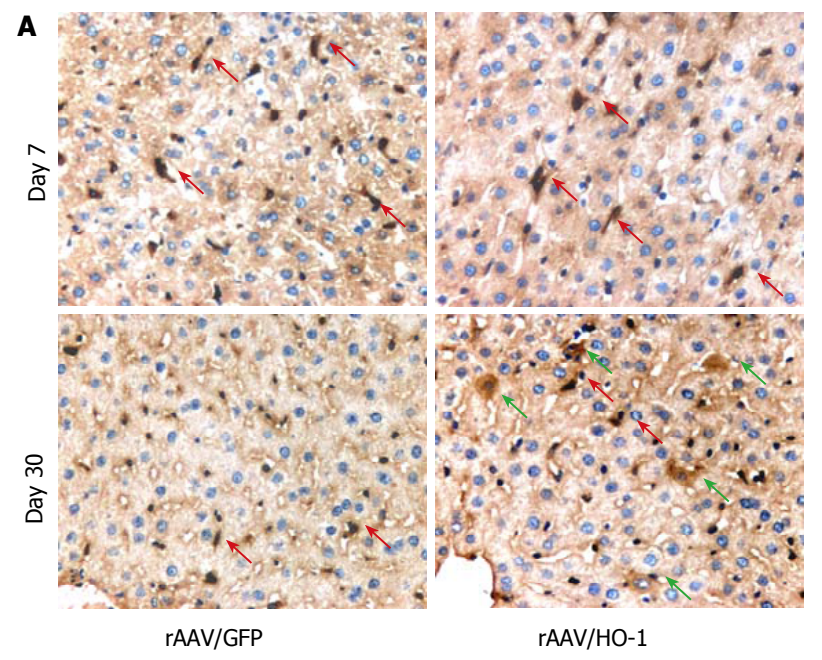

$\square$ rAAV/GFP

B
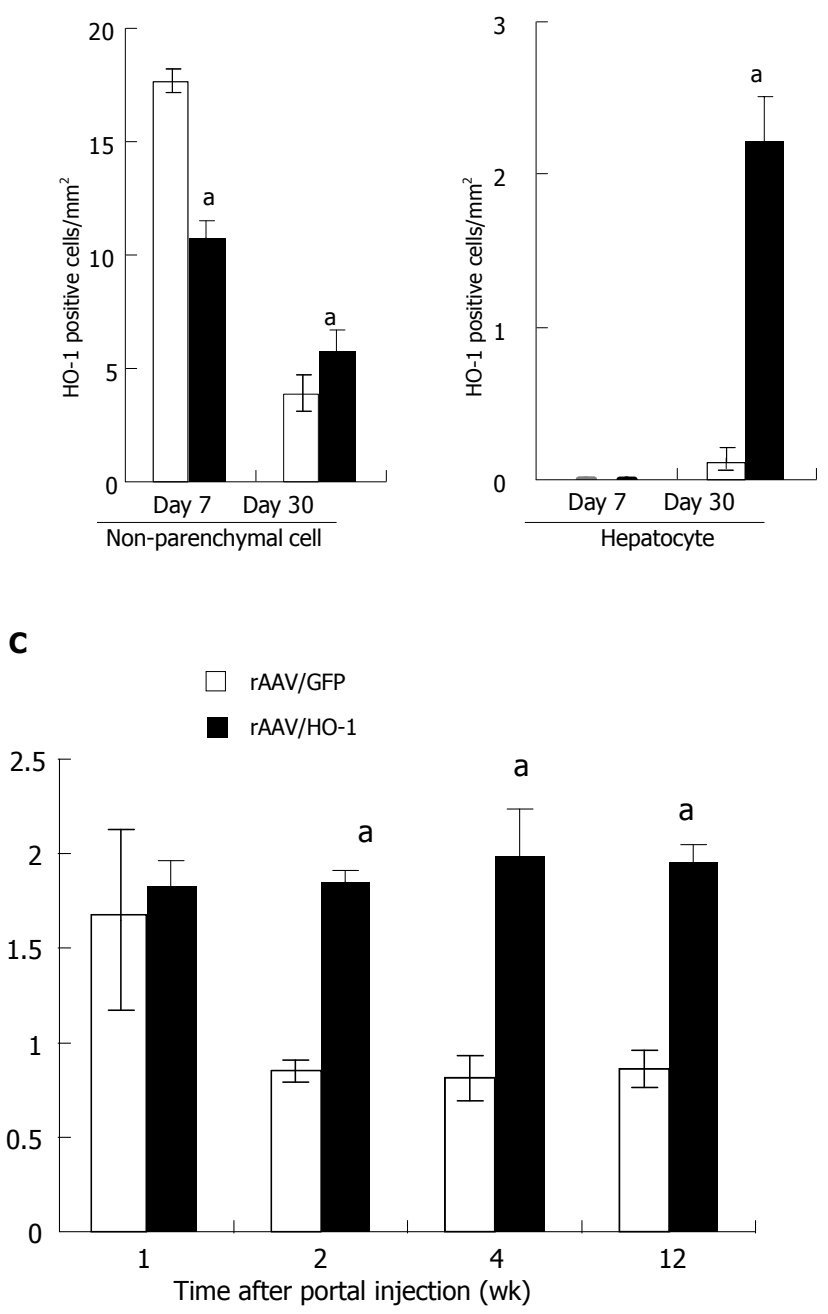

Figure $1 \mathrm{~A}$ : The expression patterns of $\mathrm{HO}-1$ in the livers after portal injection of rAAV/HO-1 in LEW rats. Red arrow indicated the HO-1-positive non-parenchymal cells; green arrow indicated the hepatocyte; $\mathrm{B}$ : The quantification of the HO-1 positive cells in the liver after administration of $\mathrm{rAAV} / \mathrm{HO}-1$. Data were presented as number of $\mathrm{HO}-1$ positive cells per $\mathrm{mm}^{2} ; n=3-5$, mean $\pm \mathrm{SE},{ }^{\mathrm{a}} P<0.05$; C: The $\mathrm{HO}$ enzymatic activity of rAAV/GFP or rAAV/HO-1 transduced livers. The data were demonstrated as the amount of generated bilirubin of microsomal protein from liver tissues and were shown as the fold changes over the normal rat liver, mean \pm SE, $n=3,{ }^{\text {a }} P<0.05$. 
A

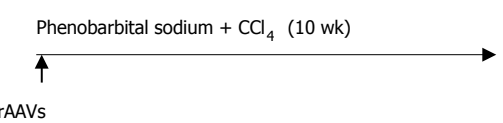

B
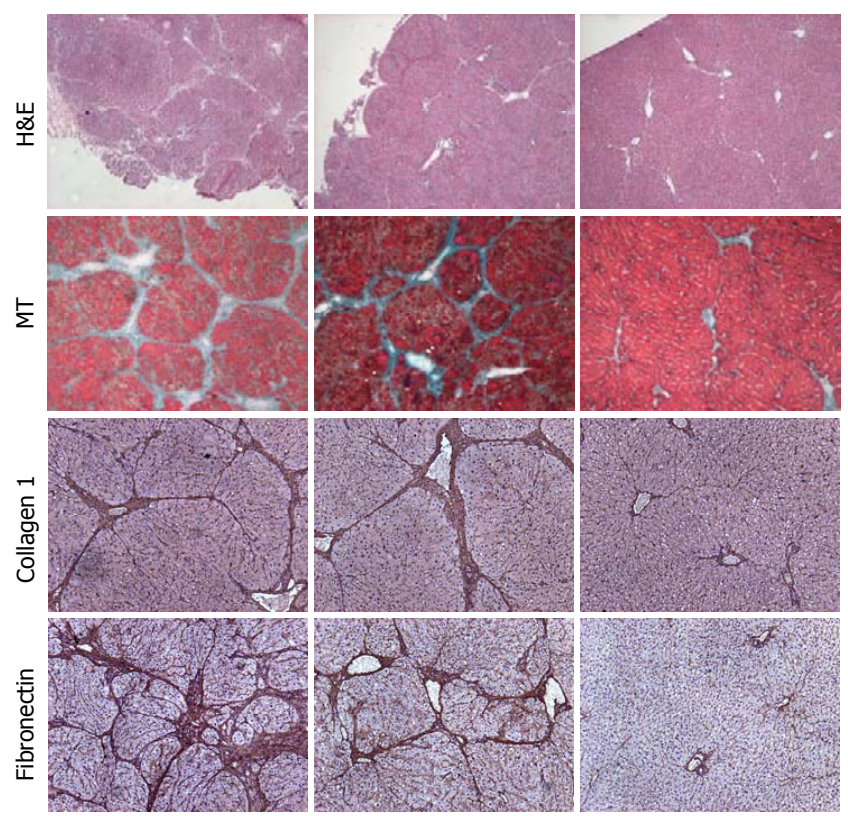

Non-transduced

$\mathbf{E}$

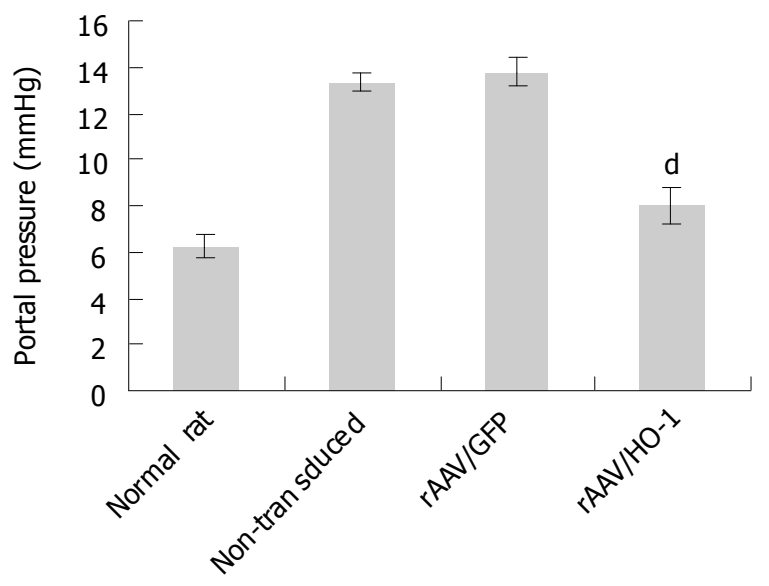

staining, $4.4 \% \pm 1.2 \%$ by fibronectin staining, $P<0.001)$. In contrast, in the livers of non-treatment or $\mathrm{rAAV} / \mathrm{GFP}$ treated groups, there was a higher level of fibrotic element deposition $(22.2 \% \pm 5.8 \%$ or $20.8 \% \pm 3.8 \%$ by MT staining, $21.9 \% \pm 5.7 \%$ or $24.5 \% \pm 2.8 \%$ by collagen $1 \alpha$ staining, $24.1 \% \pm 4.4 \%$ or $21.1 \% \pm 3.6 \%$ by fibronectin staining, Figure 2C). In addition, the beneficial effects of HO-1 on the development of liver cirrhosis could be reflected by the reduction of portal hypertension $(8.0 \pm 0.8$ $\mathrm{mmHg}$ versus $13.3 \pm 0.4 \mathrm{mmHg}$ in the non-treatment group and $13.8 \pm 0.6 \mathrm{mmHg}$ in the $\mathrm{rAAV} / \mathrm{GFP}$ treatment group, $P<0.001)$, whereas there was no significant difference at the systolic blood pressure $(81.7 \pm 0.3 \mathrm{mmHg})$ in comparison to non-treatment $(81.8 \pm 0.6 \mathrm{mmHg})$ or vector controls $(87.0 \pm 0.2 \mathrm{mmHg}, P>0.31$, Figures $2 \mathrm{D}$ and $2 \mathrm{E})$.

Stable $\mathrm{HO}$ activity protected against $\mathrm{CCl}_{4}$-mediated recurrent liver injury

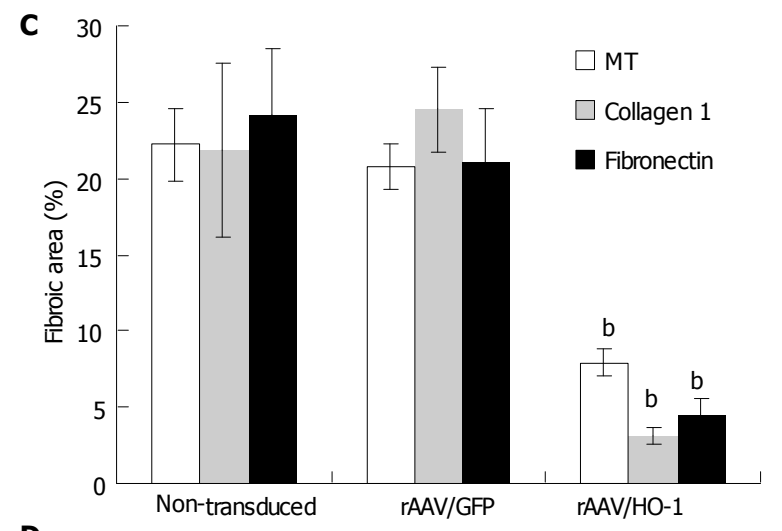

D

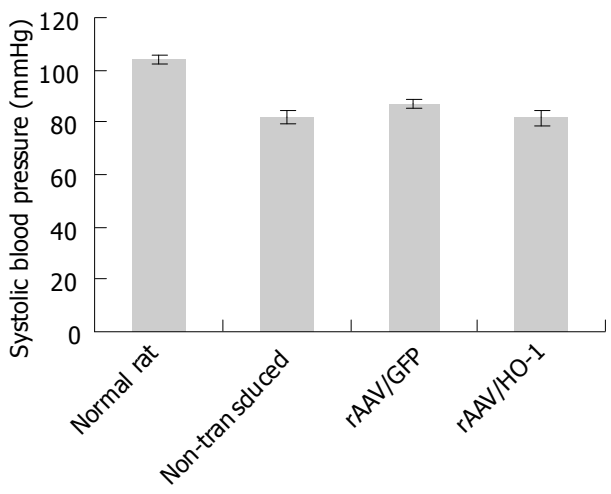

Figure 2 A: The model to induce micronodular cirrhosis in LEW rat. The rAAVs were injected through the portal vein shortly before the induction; $\mathbf{B}$ : The histology and immunohistochemistry of the livers with or without treatment at the $10^{\text {th }}$ week $(\mathrm{H}-\mathrm{E}$, original magnification $\times 40$; MT: Masson's trichrome stiaining, the fibrotic elements were stained in green, original $100 \times$; collagen 1 and fibronectin staining, original magnification $\times 100$ ); $\mathbf{C}$ : The measurement of fibrotic area in the livers at the $10^{\text {th }}$ week by the computer software as described in Materials \& Methods. Data were shown as mean \pm SE, $n=5,{ }^{b} p<0.001$; D and E: The systolic and portal pressure of rats after induction of liver cirrhosis with or without treatments. The data were shown as mean \pm SE, $n=10,{ }^{\mathrm{d}} P<0.001$.

Repeated administration of $\mathrm{CCl}_{4}$ to adult rats led to chronic liver injury with elevated plasma level of total bilirubin (no treatment group: $57.25 \pm 6.95 \mu \mathrm{mol} / \mathrm{L} ; \mathrm{rAAV} / \mathrm{GFP}$ group: $60.5 \pm 4.87 \mu \mathrm{mol} / \mathrm{L}$ ) and ALT (non-treatment group: $4522 \pm 334 \mathrm{IU} / \mathrm{L} ; \mathrm{rAAV} / \mathrm{GFP}$ group: $6552 \pm 1363 \mathrm{IU} / \mathrm{L}$, $n=5)$. Increasing $\mathrm{HO}$ activity in the liver by $\mathrm{rAAV} / \mathrm{HO}-1$ significantly improved the liver function of rats under long-term $\mathrm{CCl}_{4}$ toxicity, the amount of total bilirubin and ALT decreased dramatically in the $\mathrm{rAAV} / \mathrm{HO}-1$-treated rats in comparison to non-treatment or rAAV/GFP controls (total bilirubin: $6.20 \pm 3.49 \mu \mathrm{mol} / \mathrm{L}$; ALT: $199.6 \pm$ $80.5 \mathrm{IU} / \mathrm{L}, n=5, P<0.005$, Figures $3 \mathrm{~A}$ and $3 \mathrm{~B})$. To further examine the protective effects of over-expressing HO-1 in the livers, we determined the transcript level of apoptotic genes and energy exchanges of livers under long-term $\mathrm{CCl}_{4}$ toxicity. Rnase protection assay showed the transcript level of Fas, caspase 3 , and BAX genes significantly diminished in the $\mathrm{rAAV} / \mathrm{HO}-1$-transduced livers $(n=3, P<0.05$, 
A

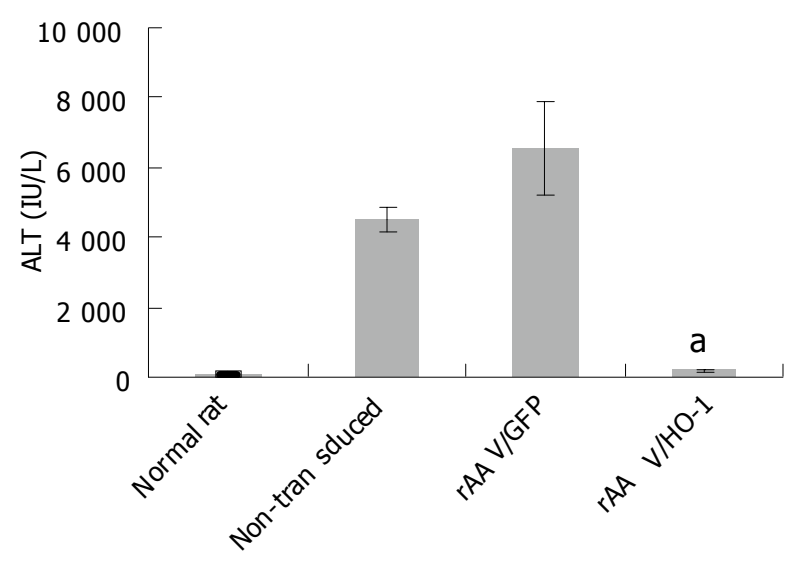

B

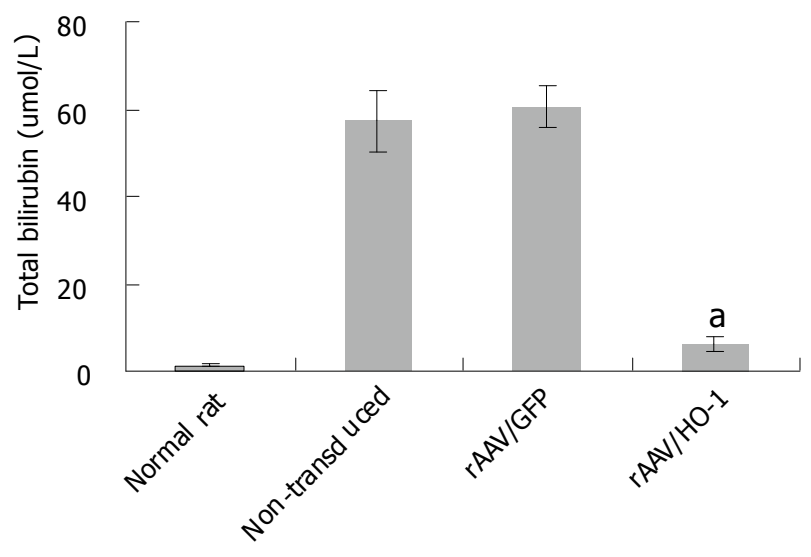

C

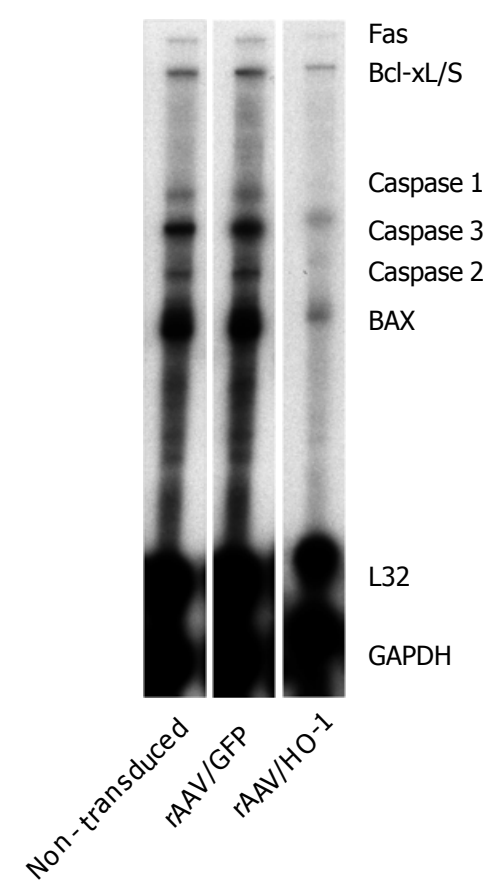

Figures 3C and 3D), whereas these genes were strongly expressed in the non-transduced or $\mathrm{rAAV} / \mathrm{GFP}$-transduced livers. The beneficial effects of $\mathrm{HO}-1$ on $\mathrm{CCl}_{4}$-mediated chronic liver injury were also shown by the improvement of liver energy exchanges. Over-expression of HO-1 by rAAV significantly improved the intrahepatic ATP level

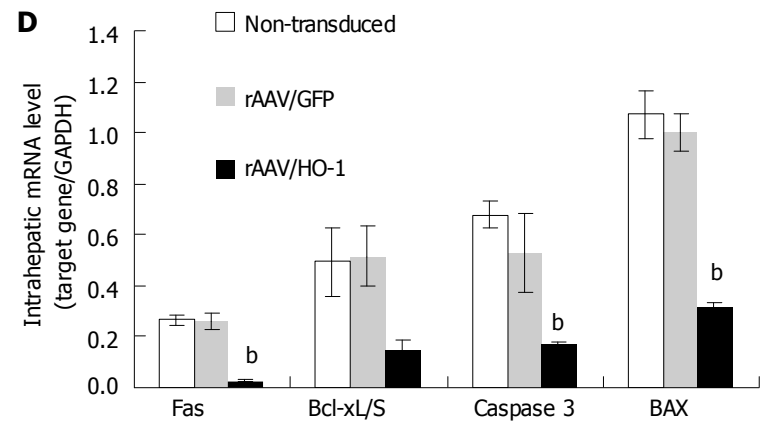

$\mathbf{E}$

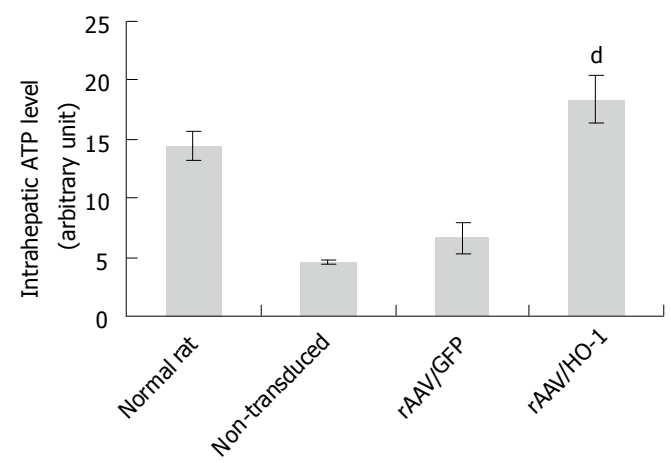

Figure $3 \mathbf{A}$ and $\mathbf{B}$ : The liver function of rats with or with treatment under long-term $\mathrm{CCl}_{4}$ toxicity was presented by the determination of plasma ALT and total bilirubin level. The data was shown as mean \pm SEM, $n=5-10,{ }^{\mathrm{a}} P<0.001$; $\mathbf{C}$ and $\mathbf{D}$ : The representative picture of the expression patterns of apoptotic genes in the livers at the $10^{\text {th }}$ week. The mRNA level of genes was detected by RNase protection assay. The quantification of the expression level was measured by phosphoimager as described in Materials \& Methods. The data were shown as mean $\pm \mathrm{SE}, n=3-5$, ${ }^{\mathrm{b}} P<0.05$; E: The ATP level of the livers of rats with or without treatments at the $10^{\text {th }}$ wk, $n=5-10,{ }^{\mathrm{d}} P<0.001$.

in $\mathrm{rAAV} / \mathrm{HO}-1$ transduced liver in comparison with nontreatment or $\mathrm{rAAV} / \mathrm{GFP}$-transduced livers of rats under long-term $\mathrm{CCl}_{4}$ toxicity ( $n=3-5, P<0.05$; Figure $3 \mathrm{E}$ ).

Stable $\mathrm{HO}$ activity suppresses the pro-inflammatory and pro-fibrogenic responses in $\mathrm{CCl}_{4}$-treated rats

To characterize the effects of HO-1 on the chronic inflammatory response followed by liver injury, we examined the histopathological parameters of liver tissues and transcript or protein level of pro-inflammatory cytokine-MIF. A large amount of ED1-positive (infiltrating) macrophages accumulated in the portal tract areas in the non-transduced or rAAV/GFP-transduced livers, whereas only a few ED1-positive macrophages were found in $\mathrm{rAAV} / \mathrm{HO}$ 1-transduced livers (Figure 4A). In contrast, there was no significant change in the number of ED2-positive (tissueresidential) macrophages in the livers of $\mathrm{CCl}_{4}$-treated rats. In consistent with the immunohistochemical stainings, detection of intrahepatic mRNA level by Rnase protection assay and serum levels of MIF by ELISA method showed significant reduction of the expression level of MIF in rAAV/HO-1-treated rats in comparison to non-treatment or $\mathrm{rAAV} / \mathrm{GFP}$ controls $(n=3-5, P<0.001$, Figures $4 \mathrm{~B}$ and $4 \mathrm{C})$.

To examine the effects of $\mathrm{rAAV} / \mathrm{HO}-1$ on the fibrogenic process after liver injury, we next examined the 
expression patterns of pro-fibrogenic cytokine-TGF- $\beta 1$, which plays an important role in the activation and transition of HSCs to myofibroblast-like cells after liver injury. Immunohistochemistry showed that TGF- $\beta 1$ was highly expressed in the portal tract areas in the livers of longterm $\mathrm{CCl}_{4}$-treated rats. In contrast, only a minimal number of cells expressed TGF- $\beta 1$ in rAAV/HO-1-transduced livers of rats under the same $\mathrm{CCl}_{4}$ protocol (Figure $4 \mathrm{~A}$ ). Parallel to the immunohistochemical stainings, RNase protection assay also showed significant reduction in the transcript level of TGF- $\beta 1$ in $\mathrm{rAAV} / \mathrm{HO}-1$-transduced livers $(n=3-5, P<0.001$, Figure 4B). This finding was associated with the decreased number of activated HSCs (desminpositive) in rAAV/HO-1-transduced livers (Figure 4A).

\section{DISCUSSION}

There is a wide range of factors can result in hepatocellular injury. However, the primary response leading to subsequent pro-inflammatory and pro-fibrogenic responses in liver is extraordinary similar ${ }^{[14]}$. Analysis of clinical parameters based on the treatment of primary liver disease showed encouraging results in the decrease of the severity of liver fibrosis/cirrhosis ${ }^{[15,16]}$. However, none of anti-fibrotic treatment has been shown clinically effective. A number of therapeutic approaches targeting on antioxidant, anti-inflammatory response, suppression of HSC activation, induction of HSC apoptosis or increase of the degradation of extracellular matrix have been shown effective in the attenuation of the severity of liver fibrosis/cirrhosis in various animal models ${ }^{[14]}$. Most of them, however, cannot easily translate to the clinical setting, because the majority of approaches focus on the single step of disease progression and the clinical situation is far more complex than that in the experimental setting. Thus, it is still urged to find out a therapeutic target that has multiple effects on disease progression and can be applied potentially in the clinical setting.

HO-1-mediated anti-apoptotic and anti-inflammatory activities are among the most attractive mechanisms in cellular protection ${ }^{[17]}$. In fact, HO-1 only expresses in a subpopulation of Kupffer cells in normal liver, whereas a small amount of HO-2 is constitutively being expressed in hepatocyte ${ }^{[3,4]}$. None of them expresses in sinusoidal endothelial cells and hepatic stellate cells ${ }^{[3]}$. However, a significant increase in HO-1 expression was observed on the whole organ level under stress conditions ${ }^{[4]}$. In the liver with acute injury, HO-1 was expressed in the majority of Kupffer cells and infiltrating macrophages, which might function as a feedback loop to control the macrophage activation ${ }^{[18-20]}$. Although the whole $\mathrm{HO}$ activity increases dramatically, the need for the liver to overcome the insults of cellular injury seems to be relatively insufficient. Increasing $\mathrm{HO}$ activity by introduction of exogenous HO-1 by $\mathrm{rAAV} / \mathrm{HO}-1$ in our model that significantly improved the long-term outcomes of $\mathrm{CCl}_{4}$-induced liver cirrhosis could be based on (1) the anti-apoptotic effects of HO-1 on hepatocyte; (2) the anti-inflammatory effects of HO-1 on the control of the cellular response of hepatocyte in the production of MIF under stress and/or injury condi-
A

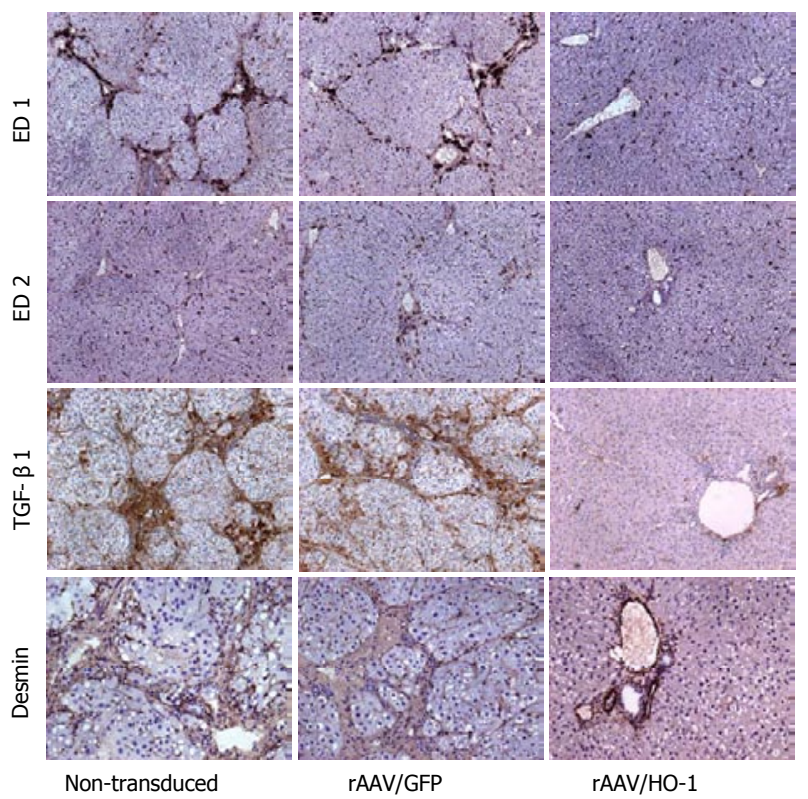

B
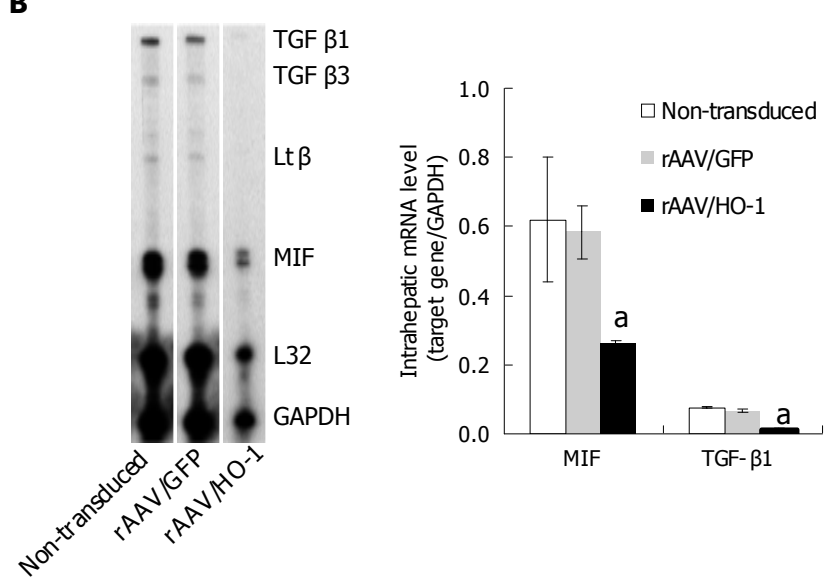

C

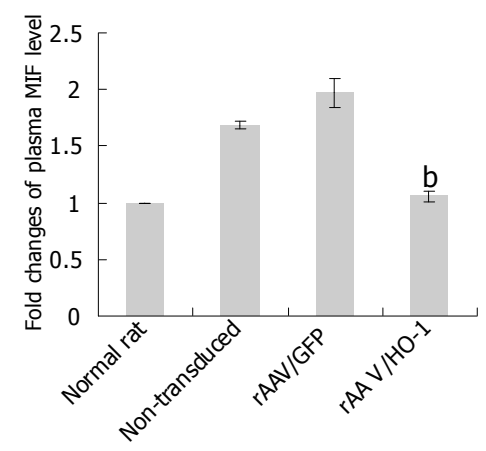

Figure 4 A: The representative pictures of pro-inflammatory and pro-fibrogenic responses in the livers of rats with or without treatment at the $10^{\text {th }}$ week. Infiltrating macrophage (ED1), tissue residential macrophages (ED2), TGF- $\beta 1$, and activated hepatic stellate cells (desmin) were detected by immunohistochemistry; original magnification, $\times 100$; $\mathbf{B}$ : The profile of pro-inflammatory and profibrogenic cytokine expression. The level of mRNA was detected by RNase protection assay and was quantified by phosphoimager, $n=3-5,{ }^{a} P<0.05$; $\mathbf{C}$ : The plasma level of macrophage migration inhibitory factor (MIF) was detected by ELISA. The data were shown as fold changes of over the level in normal rat, $n=3-5,{ }^{b} P<0.001$. 
tions and the suppression of the macrophage activation; and (3) the anti-fibrogenic effects of HO-1 on the suppression of the collagen synthesis and/or proliferation of activated HSCs.

Improvement of liver function under long-term $\mathrm{CCl}_{4}$ toxicity by $\mathrm{rAAV} / \mathrm{HO}-1$ may reflect the fact that the expression of HO-1 in the hepatocyte was able to prevent liver damage, which was supported by the down-regulation of pro-apoptotic genes and enhancement of liver ATP level in our model. In acute liver injury and ischemia/ reperfusion injury of transplanted liver, recent data suggested that the resistance of HO-1 expressing cells to the pro-apoptotic stimuli might be directly through its enzymatic product $\mathrm{CO}$ and/or indirectly through the induction of the $\mathrm{Fe}^{2+}$-sequestering protein ferritin. Exposure of $\mathrm{CO}$ to the primary hepatocyte could prevent the tumor necrosis factor- $\alpha$-mediated and anti-CD95-mediated apoptotic events through the down-regulation of caspase- 3 activity ${ }^{[21]}$, whereas the induction of ferritin suppressed serumdeprived or oxidative stress-mediated hepatocyte apoptosis by modulation of intracellular $\mathrm{Fe}^{2+}$ level and inhibition of $\mathrm{Fe}^{2+}$-mediated conversion of hydrogen peroxide into $\mathrm{OH}^{-}$and $\mathrm{OH}$ through the Fenton reaction ${ }^{[7,22]}$. In addition to antiapoptotic effects, HO-1 could also suppress the production of pro-inflammatory cytokine-MIF production in a human primary hepatocyte culture (Tsui TY, et al. unpublished data). This may suggest that HO-1 can function as homeostatic molecule in the prevention of apoptotic event and the control of cellular response.

HO-1 can be induced in various cell types including HSC through direct or indirect mechanisms. Our data are consistent with a recent finding in primary human HSC culture showing that the induction of HO-1 expression in HSC suppressed the transcript level of pro-collagen $1 \alpha$ and serum-mediated HSC proliferation ${ }^{[23]}$. This may suggest that HO-1 can serve as a negative regulator in the control of HSC activation and proliferation. Thus, less accumulation of fibrotic elements and prevention of the development of portal hypertension in $\mathrm{rAAV} / \mathrm{HO}-1$-transduced animals might reflect the outcomes of cellular protection, anti-inflammatory and anti-fibrogenic responses. Although further investigation is needed to clarify the mechanisms in more details, increased $\mathrm{HO}$ activity in liver and systemic effects of the products of $\mathrm{HO}$ enzymatic activity can be the key in the control of the development of cirrhosis and portal hypertension in our model.

In conclusion, our data demonstrated that enhancement the HO activity in a stable manner can suppresses the pathophysiological changes of cirrhosis. In addition, rAAV-mediated gene transfer may represent an attractive approach in controlling the development of cirrhosis. However, further studies should be carried out in order to answer the question of whether the rAAV approach is suitable for the hepatitis virus-mediated chronic liver injury and the subsequent outcome.

\section{REFERENCES}

1 Maines MD. The heme oxygenase system: a regulator of second messenger gases. Annu Rev Pharmacol Toxicol 1997; 37:
517-554

2 Schuller DJ, Wilks A, Ortiz de Montellano PR, Poulos TL. Crystal structure of human heme oxygenase-1. Nat Struct Biol 1999; 6: 860-867

3 Goda N, Suzuki K, Naito M, Takeoka S, Tsuchida E, Ishimura Y, Tamatani T, Suematsu M. Distribution of heme oxygenase isoforms in rat liver. Topographic basis for carbon monoxidemediated microvascular relaxation. J Clin Invest 1998; 101: 604-612

4 Bauer I, Wanner GA, Rensing H, Alte C, Miescher EA, Wolf B, Pannen BH, Clemens MG, Bauer M. Expression pattern of heme oxygenase isoenzymes 1 and 2 in normal and stressexposed rat liver. Hepatology 1998; 27: 829-838

5 Kato Y, Shimazu M, Kondo M, Uchida K, Kumamoto Y, Wakabayashi G, Kitajima M, Suematsu M. Bilirubin rinse: A simple protectant against the rat liver graft injury mimicking heme oxygenase-1 preconditioning. Hepatology 2003; 38: 364-373

6 Kyokane T, Norimizu S, Taniai H, Yamaguchi T, Takeoka S, Tsuchida E, Naito M, Nimura Y, Ishimura Y, Suematsu M. Carbon monoxide from heme catabolism protects against hepatobiliary dysfunction in endotoxin-treated rat liver. Gastroenterology 2001; 120: 1227-1240

7 Ferris CD, Jaffrey SR, Sawa A, Takahashi M, Brady SD, Barrow RK, Tysoe SA, Wolosker H, Barañano DE, Doré S, Poss $\mathrm{KD}$, Snyder SH. Haem oxygenase-1 prevents cell death by regulating cellular iron. Nat Cell Biol 1999; 1: 152-157

8 Makino N, Suematsu M, Sugiura Y, Morikawa H, Shiomi S, Goda N, Sano T, Nimura Y, Sugimachi K, Ishimura Y. Altered expression of heme oxygenase- 1 in the livers of patients with portal hypertensive diseases. Hepatology 2001; 33: 32-42

9 Chen YC, Ginès, Yang J, Summer SN, Falk S, Russell NS, Schrier RW. Increased vascular heme oxygenase-1 expression contributes to arterial vasodilation in experimental cirrhosis in rats. Hepatology 2004; 39: 1075-87

10 Arguedas MR, Drake BB, Kapoor A, Fallon MB. Carboxyhemoglobin levels in cirrhotic patients with and without hepatopulmonary syndrome. Gastroenterology 2005; 128: 328-333

11 Tsui TY, Wu X, Lau CK, Ho DW, Xu T, Siu YT, Fan ST. Prevention of chronic deterioration of heart allograft by recombinant adeno-associated virus-mediated heme oxygenase-1 gene transfer. Circulation 2003; 107: 2623-2629

12 Wu XB, Dong XY, Wu ZJ, Ho YD. A novel method for purification of recombinant adeno-associated virus vectors on a large scale. Chinese Sci Bull 2001; 46: 484-489

13 Proctor E, Chatamra K. High yield micronodular cirrhosis in the rat. Gastroenterology 1982; 83: 1183-1190

14 Rockey DC. The cell and molecular biology of hepatic fibrogenesis: Clinical and therapeutic implications. Clin Liver Dis 2000; 4: 319-355

15 Dienstag JL, Goldin RD, Heathcote EJ, Hann HW, Woessner M, Stephenson SL, Gardner S, Gray DF, Schiff ER. Histological outcome during long-term lamivudine therapy. Gastroenterology 2003; 124: 105-117

16 Arif A, Levine RA, Sanderson SO, Bank L, Velu RP, Shah A Mahl TC, Gregory DH. Regression of fibrosis in chronic hepatitis $\mathrm{C}$ after therapy with interferon and ribavirin. Dig Dis $\mathrm{Sci}$ 2003; 48: 1425-1430

17 Otterbein LE, Soares MP, Yamashita K, Bach FH. Heme oxygenase-1: unleashing the protective properties of heme. Trends Immunol 2003; 24: 449-455

18 Paxian M, Rensing H, Rickauer A, Schönhofen S, Schmeck J, Pannen BH, Bauer I, Bauer M. Kupffer cells and neutrophils as paracrine regulators of the heme oxygenase-1 gene in hepatocytes after hemorrhagic shock. Shock 2001; 15: 438-445

19 Otterbein LE, Bach FH, Alam J, Soares M, Tao Lu H, Wysk M, Davis RJ, Flavell RA, Choi AM. Carbon monoxide has antiinflammatory effects involving the mitogen-activated protein kinase pathway. Nat Med 2000; 6: 422-428

20 Lee TS, Tsai HL, Chau LY. Induction of heme oxygenase-1 expression in murine macrophages is essential for the antiinflammatory effect of low dose 15-deoxy-Delta 12,14-prostaglandin J2. J Biol Chem 2003; 278: 19325-19330

21 Sass G, Soares MC, Yamashita K, Seyfried S, Zimmermann 
WH, Eschenhagen T, Kaczmarek E, Ritter T, Volk HD, Tiegs G. Heme oxygenase- 1 and its reaction product, carbon monoxide, prevent inflammation-related apoptotic liver damage in mice. Hepatology 2003; 38: 909-918

22 Berberat PO, Katori M, Kaczmarek E, Anselmo D, Lassman C, Ke B, Shen X, Busuttil RW, Yamashita K, Csizmadia E, Tyagi S, Otterbein LE, Brouard S, Tobiasch E, Bach FH, Kupiec-
Weglinski JW, Soares MP. Heavy chain ferritin acts as an antiapoptotic gene that protects livers from ischemia reperfusion injury. FASEB J 2003; 17: 1724-1726

23 Li L, Grenard P, Nhieu JT, Julien B, Mallat A, Habib A, Lotersztajn $S$. Heme oxygenase- 1 is an antifibrogenic protein in human hepatic myofibroblasts. Gastroenterology 2003; 125: 460-469

S- Editor Wang J L- Editor Zhang JZ E- Editor Zhang Y 